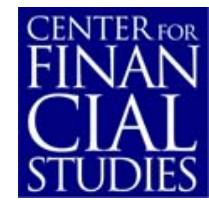

No. $2011 / 03$

Is BEST Really Better?

Internalization of Orders in an

Open Limit Order Book

Joachim Grammig and Erik Theissen 


\section{Center for Financial Studies}

The Center for Financial Studies is a nonprofit research organization, supported by an association of more than 120 banks, insurance companies, industrial corporations and public institutions. Established in 1968 and closely affiliated with the University of Frankfurt, it provides a strong link between the financial community and academia.

The CFS Working Paper Series presents the result of scientific research on selected topics in the field of money, banking and finance. The authors were either participants in the Center's Research Fellow Program or members of one of the Center's Research Projects.

If you would like to know more about the Center for Financial Studies, please let us know of your interest.

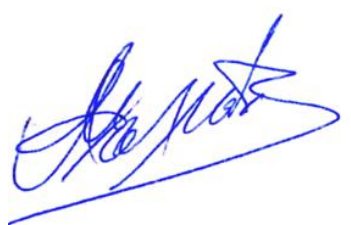

Prof. Michalis Haliassos, Ph.D.
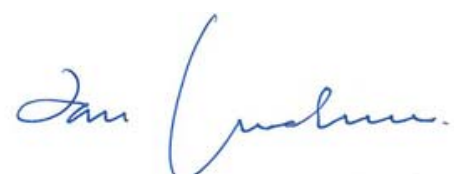

Prof. Dr. Jan Pieter Krahnen

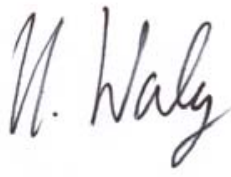

Prof. Dr. Uwe Walz 


\title{
Is BEST Really Better? Internalization of Orders in an Open Limit Order Book*
}

\author{
Joachim Grammig $^{1}$ and Erik Theissen ${ }^{2}$
}

\author{
January 2011
}

\begin{abstract}
This paper studies the market quality of an internalization system which is designed as part of an open limit order book (the Xetra system operated by Deutsche Börse AG). The internalization sys-tem (Xetra BEST) guarantees a price improvement over the inside spread in the Xetra order book. We develop a structural model of this unique dual market environment and show that, while adverse selection costs of internalized trades are significantly lower than those of regular order book trades, the realized spreads (the revenue earned by the suppliers of liquidity) is significantly larger. The cost savings of the internalizer are larger than the mandatory price improvement. This suggests that internalization can be profitable both for the customer and the internalizer.
\end{abstract}

JEL Classification: G10

Keywords: Internalization, Execution Quality, Adverse Selection Costs

\footnotetext{
* We thank two anonymous referees, Miroslav Budimir, Oliver Maurer, Uwe Schweickert and seminar participants at the University of Frankfurt/Main, KU Leuven, CORE/Louvain-La-Neuve, the University of Porto, ISCTE Lisbon and at Humboldt University Berlin for their helpful comments and Oliver Wünsche for excellent research assistance. We are grateful to Deutsche Börse AG for providing access to the data. Uwe Schweickert offered invaluable expertise in the trading systems and support for our work.

1 University of Tübingen, Department of Economics, Mohlstr. 36. 72074 Tübingen, Germany, E-mail: joachim.grammig@unituebingen.de, Phone: +49 7071 2976009, fax: +49 7071 295546; 


\section{Introduction}

Internalization is a practice by which banks or brokers receiving (retail) customer orders do not route these orders to the exchange but rather execute them against their own book. Internalization has been, and still is, a controversial issue. Proponents argue that internalization realizes cost savings and can thus be advantageous for both the bank and the customer. Critics, on the other hand, argue that internalization results in fragmentation and cream skimming, and may be detrimental to market quality.

In the pre-MiFID era the EU member states have taken very different regulatory stances on internalization. France and Italy had adapted a "concentration rule" which required that all transactions be processed on a regulated market. Such a rule works to prohibit internalization. Other countries, such as Germany and the UK, allowed internalization. In the UK it was practiced on a large scale. Hansch, Naik and Viswanathan (1999) report that $62 \%$ of the trades in their sample from the London Stock Exchange were internalized. When, in 2002, the commission of the European Union published a draft paper for the Markets in Financial Instruments Directive (MiFID) it took a very liberal approach to internalization. A hefty debate ensued. The final version of the directive takes a somewhat more restrictive approach. It allows internalization but requires internalizers to "make public their quotes on a regular and continuous basis during normal trading hours".

In this paper we address the economic issues involved. Internalization, if practiced singlehandedly by brokers, ${ }^{1}$ has two potential drawbacks (see, e.g., Easley, Kiefer and O'Hara 1996,

1 Single-handed internalization is very common in the US. An example of single-handed internalization in Germany is the PIP program operated by Deutsche Bank until October 2007. 
Theissen 2002). First, internalized orders are not executed on the exchange but are rather executed in an in-house market. This leads to a fragmentation of the order flow which, in turn, may reduce the trading volume and the liquidity of the main market. Second, typically only orders satisfying specific criteria are internalized. The most important criteria are that a) the order is submitted by a retail customer and b) the order is small. Empirical evidence (e.g. Chakravarty 2001 and Linnainmaa 2003) suggests that retail customers submitting small orders are unlikely to possess private information on the value of the assets they trade. Therefore, the internalizer faces a low risk of trading with a better informed counterparty and, therefore, faces low adverse selection costs - internalizers "skim the cream" off the order flow (e.g. Easley, Kiefer and O'Hara 1996). The flip side of the coin is, however, that the non-internalized orders which are routed to the main market have an increased probability of being informed. The adverse selection risk faced by the suppliers of liquidity on the main market thus increases.

We analyze Xetra BEST, a system introduced by Deutsche Börse AG in 2002. Xetra BEST is unique in several respects. First, the system requires that customer orders are filled at a price which is more favorable than the price the order would receive if it was routed to the Xetra order book instead. The minimum price improvement was 1 cent per share during our sample period. ${ }^{2}$ Second, Xetra BEST allows internalization on a platform which is operated by the exchange. Therefore, the trading volume executed on the exchange is not reduced, and fragmentation is not much of an issue. Consequently, in our analysis we focus on the cream skimming hypothesis. We test it by comparing the adverse selection costs of internalized orders to those of orders executed on the main market. To this end we develop a structural model of the

2 The minimum price improvement has been reduced to 0.1 cent in 2007. 
specific dual market structure of Xetra BEST. The model is an extension of the approach put forth in Glosten and Harris' (1988) seminal paper.

One important question that we do not address in this paper is whether internalization is detrimental to market quality. According to the cream skimming hypothesis internalization diverts easy-to-fill orders (i.e., orders which are unlikely to be information-based) away from the main market. Consequently the adverse selection costs in the main market should increase. This yields the prediction that the introduction of Xetra BEST leads to an increase in the spreads in the Xetra order book. Testing this prediction is very difficult for two reasons. First, the market share of Xetra BEST is very low (1.5\% of the number of transactions, $0.25 \%$ of the trading volume; see section 3). Therefore, any effect on the quality of the main market will be small and will be almost impossible to identify empirically. Second, the event of interest - the introduction of Xetra BEST - occurred at the same time for all sample stocks. In such a setting it is difficult to appropriately control for other factors affecting liquidity (see Maher, Swan and Westerholm 2008). For these reasons we do not attempt to analyze whether the quality of the main market has changed upon introduction of Xetra BEST. Rather, we analyze Xetra and Xetra BEST transactions with respect to the quality of execution, the magnitude of the adverse selection costs, and the realized spread earned by the suppliers of liquidity.

Our results provide clear evidence of cream skimming. Realized spreads ${ }^{3}$ are significantly higher for orders executed in Xetra BEST than for orders executed in Xetra, and adverse selec-

3 The effective bid-ask spread, defined as the difference between the transaction price and the midpoint of the best bid and the best ask quote at the time the transaction occurs, is a widely used measure of the implicit transaction cost of a trade. The effective spread can be decomposed into a portion that measures the losses of the suppliers of liquidity to traders with superior information (the adverse selection component) and the re- 
tion costs in Xetra BEST are significantly lower than those in the main market. Internalizers thus earn realized spreads that are larger than those earned by the suppliers of liquidity on the main market. This is true even after taking into account the mandatory price improvement. Consequently, internalization can be profitable both for the customer (who receives the price improvement) and for the broker (who earns a large realized spread). The amount of the minimum price improvement determines how the cost savings are shared between the customer and the internalizing bank or broker.

Our paper is related to previous studies of internalization and the related phenomena of preferencing and payment for order flow. ${ }^{4}$ On balance, these papers conclude that market quality is not negatively affected by internalization. There appears to be, however, some evidence of cream skimming, as documented in Easley, Kiefer and O'Hara (1996). Our paper offers three contributions to this literature. First, we analyze the effects of internalization in a fully electronic auction market. This contrasts with previous papers analyzing the floor-based specialist system of the NYSE or the dealer markets of Nasdaq and the London Stock Exchange.

maining portion, the realized spread. The realized spread covers the order processing costs and also captures profits the suppliers of liquidity may be earning.

4 Battalio, Jennings and Selway (2001), Hansch, Naik and Viswanathan (1999) and Peterson and Sirri (2003) compare execution costs for preferenced and non-preferenced orders. Battalio (1997) and Battalio, Greene and Jennings (1997) analyze whether the execution quality of the main market was affected by the introduction of preferencing and payment for order flow arrangements. Easley, Kiefer and O'Hara (1996) compare the probability of informed trades on two exchanges known to execute a large fraction of purchased order flow to the probability of informed trading on the NYSE. Bloomfield and O'Hara (1998) analyze the effect of preferencing in an experimental setting. Battalio and Holden (2001), Kandel and Marx (1999) and Parlour and Rajan (2001) develop theoretical models of payment for order flow arrangements. 
Second, we analyze internalization on a system that is operated by the exchange itself. The German Stock Exchange has deliberately implemented rules aiming at mitigating the potentially adverse effects of internalization on the quality of the main market. Third, the paper proposes a new methodology to estimate spread components in parallel markets. Our extension of the Glosten and Harris (1988) model has several potential applications, e.g. it could be used to analyze the competition between a regulated market and an electronic communication network $(\mathrm{ECN})$.

The remainder of the paper is organized as follows. In section 2 we describe Xetra BEST in detail. In section 3 we introduce our dataset and present descriptive statistics. Section 4 develops the empirical methodology and presents and discusses the main results. Section 5 concludes.

\section{Market Structure}

Xetra is an anonymous electronic open limit order book. Trading starts at 9 a.m. with an opening call auction and (during our sample period) ends at 8 p.m. with a closing auction. ${ }^{5}$ There are two intraday call auctions at 1 p.m. and 5.30 p.m. Liquidity is supplied by limit order traders. Orders are matched based on price and time priority. For less liquid stocks there are designated market makers, but this does not apply to our sample stocks. Although Xetra faces competition from several floor-based exchanges (the largest being the Frankfurt Stock Exchange) it is the dominant market for German blue chips. Its market share is well above $90 \%$.

5 Since November 2003, the closing auction takes place at 5.30 p.m. and there is only one intraday auction. 
Xetra BEST was introduced in September 2002 and is an integral part of Xetra. ${ }^{6}$ Xetra mem- $^{-}$ bers (brokers and banks) who act as so-called best executors have the right to execute qualifying customer orders against their own account using Xetra BEST as a trading platform. The best executors are thus acting as market makers.

Only market orders and marketable limit orders ${ }^{7}$ submitted by retail customers are eligible for execution in Xetra BEST. Orders executed in Xetra BEST receive a mandatory price improvement to be granted by the best executor. The execution price is at least one cent per share (the minimum price increment in $\mathrm{Xetra}^{8}$ ) better than the reference price. The reference price, in turn, is the price at which the order would execute if it was submitted to Xetra instead. For orders not exceeding the depth at the best bid or ask, the reference price is the best bid or ask. For orders exceeding the depth at the best quotes the reference price is calculated as the volume-weighted average of the relevant limit orders in the book. In this case all limit orders in the book that are priced better than the reference price are executed ("clean-up print"). Therefore, price priority is not violated. Brokerage commissions do not depend on whether an order is executed as a regular Xetra trade or as a Xetra BEST trade.

The best executor specifies the maximum volume she is willing to trade on either side of the market, and the amount of price improvement that is granted, and enters the corresponding

6 In 2007 Xetra BEST has been redesigned. Among the most important changes is a reduction of the minimum price improvement from 1 cent to 0.1 cent. The description in the text refers to the version of Xetra BEST which was in operation during our sample period.

7 A marketable limit order is a limit order to buy with a price limit that is equal to or higher than the current best ask or a limit order to sell with a price limit that is equal to or lower than the current best bid. Marketable limit orders are treated like market orders; i.e., they are immediately executed against the current best bid or ask. 
values into the system. ${ }^{9}$ It is important to note that these parameters are general instructions to the trading system that are not changed frequently. Hence, the best executer is not in a position to decide whether a specific order will be internalized or routed to the Xetra order book. This implies that the best executor cannot condition execution in Xetra BEST on the current spread in the order book. This lack of discretion may make internalization unattractive at first sight. Remember, though, that the cream skimming hypothesis introduced above is predicated on the assumption (and on supportive empirical evidence) that small orders submitted by retail customers are less likely to be based on superior information. If this is a case, a division of the order flow based on general instructions is sufficient to attain cream skimming.

When a Xetra BEST-eligible order is submitted, the system checks whether the size of the order exceeds the maximum volume specified by the best executor. It further checks whether the order is submitted during a call auction in Xetra. In both cases the order will not be executed via Xetra BEST but is automatically routed to the Xetra order book.

The system also checks whether the price improvement would result in a zero or negative spread. If the spread in the Xetra order book is one cent, then a one cent price improvement results in a negative spread for the internalizer. To see this, assume the current best bid and ask prices are 10.00 and 10.01 , respectively. A one cent price improvement implies that the internalizer sells at 10.00 (one cent lower than the current best ask) and buys at 10.01 (one cent higher than the current best bid). The resulting spread is negative. By the same argument, a two-cent spread in the order book will result in a zero-spread for the internalizer. In both cases the order will not be executed via Xetra BEST but is automatically re-routed to the Xetra order

\footnotetext{
8 The minimum tick size in Xetra has been reduced in 2007, after the end of our sample period. .

9 Best executors can choose to offer price improvements larger than 1 cent.
} 
book. This is a highly relevant case because one- and two-cent spreads are very common for liquid stocks.

Xetra BEST is fully post-trade transparent. Internalized transactions are reported immediately and are marked as "XB". This allows market participants to distinguish Xetra BEST transactions from regular order book trades. The system allows for order flow provision agreements. Under such an agreement, a broker who is not a best executor may route eligible customer orders to a best executor. In turn, the broker may receive a payment for the order routing. ${ }^{10} \mathrm{Ob}-$ viously, such an arrangement shares many similarities with the practice of payment for order flow in the US.

It has been argued that internalization, when practiced on a larger scale, may adversely affect the quality of the main market (see Biais and Davydoff 2002 and the literature addressing the cream skimming argument referred to earlier). In an attempt to counterbalance this effect, best executors are required to act as "liquidity managers" in the regular Xetra order book for those stocks for which they act as a best executor. A liquidity manager has to contribute to the liquidity of the order book by submitting limit orders. A best executor obviously has no incentive to improve the liquidity in the order book, as this would reduce the revenues earned on the internalized orders. Therefore, requiring the best executors to act as liquidity managers will only serve its purpose if the obligations of a liquidity manager are exactly specified and also enforced. Maximum spread requirements exist for non-DAX stocks but not for the component stocks of the DAX (which constitute our sample). ${ }^{11}$

10 Unfortunately, we do not have access to information on the frequency and magnitude of such payments.

11 It would be very interesting to empirically analyze the extent to which the liquidity management activities of the best executors affect the liquidity in the order book. This would, however, require a dataset which contains 
Given the design of Xetra BEST a retail customer who has decided to trade shares using a market order ${ }^{12}$ is always better off having her order executed in Xetra BEST as compared to the Xetra order book. The internalizer potentially benefits from the low adverse selection costs (see the cream skimming argument outlined above). On the other hand, he has to grant the price improvement. The relative magnitude of the cost advantage and the price improvement determines whether internalization is profitable. Whether this is the case is a question we try to answer in our empirical analysis.

\section{Data}

Our data set covers eight stocks and the period October 2002 through January 2003, a total of 84 trading days. The sample stocks are German blue chip stocks, and they are all among the constituent stocks of the DAX index. For each of the sample stocks we have a complete record of all transactions in Xetra and Xetra BEST. If a market order or marketable limit order walks up or down the Xetra order book (i.e. the order volume exceeds the depth at the best quote), the resulting transactions are recorded as one transaction at the volume-weighted average price. Besides the transaction price the data include the exact time of the trade, the volume of the trade, an indication whether the trade was buyer- or seller-initiated, and an indicator identifying trades executed in Xetra BEST.

Insert Table I about here

all limit orders submitted to the market and reveals the identity of the order submitter. Such a data set is, unfortunately, unavailable.

12 The price improvement makes market orders relatively more attractive. Therefore, the design of Xetra BEST may also have implications for the choice between market orders and limit orders. 
Table I presents descriptive statistics. The figures confirm that the sample stocks are indeed highly liquid. Even the least frequently traded stock has more than 70,000 transactions in the sample period which corresponds to roughly 860 transactions per day. The market share of Xetra BEST is rather low. Measured in number of transactions, the Xetra BEST market share amounts to $1.5 \%$ averaged across stocks. Furthermore, transactions in Xetra BEST are much smaller than regular order book trades. Measured in Euro trading volume, the Xetra BEST market share is only about $0.25 \%$.

As noted previously, the trading system automatically checks whether the price improvement would result in a zero or negative spread. If so, the order will not be executed in Xetra BEST but will be routed to the order book. There are thus orders that were originally entered as Xetra BEST orders but were eventually executed in the order book. In our data set these transactions are coded as order book trades, not as Xetra BEST trades. Given that one- and two-cent spreads are quite common for the most liquid stocks, the figures provided in Table I are likely to understate the market share of Xetra BEST.

\section{Methodology and Results}

A variety of procedures to estimate the spread and its components has been proposed in the literature. In this paper we employ two different approaches. We first compute realized spreads to measure the revenue earned by the suppliers of liquidity. We then develop a structural model that is used to estimate the adverse selection and order processing components of the spread in Xetra and Xetra BEST. For that purpose, we modify the Glosten and Harris (1988) approach to account for the specific dual market structure under scrutiny. We also estimate a restricted 
version of the model which is similar to the models considered by Huang and Stoll (1997) and Madhavan, Richardson and Roomans (1997).

\subsection{Realized Spreads}

Following Huang and Stoll (1996) realized (half) spreads are obtained by relating the price of a transaction to the quote midpoint prevailing a specified time span $\tau$ (e.g. 5 minutes) after the trade. The future midpoint serves as an estimate of the asset value. Relating the transaction price to this estimate of the asset value and averaging across trade events results in an estimate of the liquidity suppliers' gross revenue.

As our data do not contain bid-ask quotes, we cannot use the future quote midpoint to compute realized spreads. We therefore proceed as follows. We match each buyer-initiated trade with the first seller-initiated trade after at least $\tau=5$ minutes, and similarly we match each sellerinitiated trade with the first buyer-initiated trade after at least $\tau=5$ minutes. ${ }^{13}$ As a robustness check we have repeated the estimation using $\tau=1$ minute and $\tau=10$ minutes. The results were very similar and are therefore omitted from the paper.

Formally, let $P_{t}^{a}$ and $P_{t}^{b}$ denote the transaction prices for a time $t$ buyer-initiated trade (i.e., a trade at the ask price) and a seller-initiated trade (at the bid price), respectively. Then the expressions

$$
s_{t}^{R}=P_{t}^{a}-P_{t+\tau}^{b}
$$

13 Regular Xetra trades and Xetra BEST trades are pooled. Thus, a regular Xetra trade at time $t$ may be paired with a future regular Xetra trade or a Xetra BEST trade, and similarly a Xetra BEST trade at time $t$ can be paired with a future regular Xetra trade or a Xetra BEST trade. 
if the initial transaction was at the ask and

$$
s_{t}^{R}=P_{t+\tau}^{a}-P_{t}^{b}
$$

if the transaction at time $t$ was at the bid, provide estimates of the realized spread. If the first trade that occurs at least 5 minutes after the initial trade is equally likely to be buyer- or sellerinitiated, our approach will, in expectations, yield the same result as the procedure that uses the future midpoint. ${ }^{14}$

Results are presented in Panel A of Table II. The (unweighted) average realized spread in Xetra is 0.76 cents per share. The corresponding value in Xetra BEST is more than twice as high. Here, the average realized spread amounts to 1.82 cents. The relation that the realized spread in Xetra BEST is higher than the realized spread in Xetra holds for all sample stocks. Note that the figures for Xetra BEST already incorporate the price improvement. Thus, even after granting the price improvement the realized spread earned by the internalizer is larger than the realized spreads earned by the suppliers of liquidity in the Xetra order book. This implies that the subset of orders executed in Xetra BEST yields higher profits for the suppliers of liquidity than regular order book trades. A possible explanation (to be elaborated below) is that adverse selection costs are lower in Xetra BEST.

The analysis so far did not take into account that the average trade size in the two trading venues is different. We therefore repeat the analysis but now exclude all trades in the Xetra order

14 Although the order flow may be serially correlated, this correlation is unlikely to persist for five minutes. Even the least liquid stock in our sample has a transaction frequency which corresponds to an average inter-trade duration of less than one minute. Our assumption that the first trade after five minutes is buyer- or sellerinitiated with equal probability is, therefore, innocuous. 
book that are larger than the largest trade in Xetra BEST for the stock under investigation. The results are also presented in Table II. The average realized spread in Xetra now amounts to 0.86 cents, 0.1 cents larger than the average for the unrestricted sample. This suggests that realized spreads are negatively related to trade size. Realized spreads are still larger in Xetra BEST for all sample stocks. The difference is statistically significant at the $5 \%$ level for all but two stocks (see the last column in Panel A of Table II).

\section{Insert Table II about here}

Restricting the sample to trades that do not exceed the maximum trade size in Xetra BEST is a rather crude way to control for size dependence. To check the robustness of the result, we perfom an additional regression analysis that explicitly controls for the effect of trading volume on the realized spread. Specifically, we estimate the regression

$$
s_{t}^{R}=\gamma_{0}+\gamma_{1} B_{t}+\gamma_{2} \ln \left(V_{t}\right)+\varepsilon_{t}
$$

for each stock separately. $B_{t}$ is a dummy variable identifying transactions in Xetra BEST and $V_{t}$ is the volume, measured by the number of shares, of transaction $t$. Order book trades with a size exceeding the maximum trade size in Xetra BEST are excluded from the analysis. ${ }^{15}$ The results shown in Panel B of Table II confirm the negative relation between realized spread and volume. The corresponding coefficient estimates are negative and significant for all sample stocks. Our previous finding that realized spreads are significantly higher in Xetra BEST is confirmed for six of the eight sample stocks. For the remaining two stocks the difference in realized spreads is insignificant with one coefficient estimate being positive and the other one negative. The analysis of the realized spreads thus provides evidence that internalization in

\footnotetext{
15 We have also estimated the model using all observations. The results are virtually identical.
} 
Xetra BEST is profitable. Realized spreads for Xetra BEST trades are - even after taking the mandatory price improvement into account - higher than realized spreads for regular Xetra trades.

In the next section we develop and test a structural model of the specific dual market structure in order to gain insights into the reasons for the differences we uncovered.

\subsection{A Structural Model of the Dual Trading Environment}

Given that our data allows identification of trades as buyer-initiated or seller-initiated, yet do not contain quote information, it is natural to employ a spread decompostion model along the lines of Glosten and Harris (1988), Huang and Stoll (1997) and Madhavan, Richardson and Roomans (1997) for a comparison and decompostion of transaction costs in Xetra and Xetra BEST. In the context of the present paper, the Glosten and Harris (1988) model is the most suitable framework. As documented in Table I, average trade sizes in Xetra and Xetra BEST are quite different. As the execution costs and their components may depend on trade size, a model that accounts for trade size is warranted. The Glosten-Harris model is the only model to include trade size as an explanatory variable. Both Huang and Stoll (1997) and Madhavan, Richardson and Roomans (1997) assume a constant trade size. When the trade size in the Glosten-Harris model is assumed to be constant, the model reduces to the Huang-Stoll model and the Madhavan, Richardson and Roomans model (with the additional restriction of zero correlation in the order flow). Besides our full model we also estimate such a restricted version.

The basic idea of the Glosten and Harris (1988) model is that the bid-ask spread consists of two components. The first component allows the market makers (or, more generally, the sup- 
pliers of liquidity) to cover their cost of doing business and to possibly earn a profit. This component of the spread is unrelated to the value of the asset and is, therefore, transitory. It only causes the prices of subsequent transactions to "bounce" between the bid price and the ask price.

The second component arises because the suppliers of liquidity, with positive probability, trade with better informed investors. But then the fact that a transaction took place may reveal new information about the asset value. Suppliers of liquidity will update their beliefs accordingly and will adjust both their bid and ask prices. These price changes are related to the value of the asset and are therefore permanent. If the suppliers of liquidity only adjust their bid and ask prices after the transaction but do not widen the spread they would incur losses. After selling they would realize that the value of the asset is higher than they previously thought and that they sold at too low a price (and vice versa after buying). To protect against these losses the suppliers of liquidity will increase the bid-ask spread beyond the level that would obtain in a world without information asymmetries. ${ }^{16}$ The second component of the spread is therefore referred to as adverse-selection component.

In the Glosten and Harris (1988) model the adjustment of the quotes after a trade will depend on the information content of the transaction. The original Glosten and Harris (1988) model assumes that market participants learn a) the direction of the trade (i.e., whether it was buyerinitiated or seller-initiated) and b) the transaction volume. The trade direction determines the sign of the change in the quotes, the volume determines the size of the change. The intuition for the size-dependence is as follows. Traders possessing superior information will prefer to make large trades. But then, the probability that the counterparty to a trade possessed superior 
information is a function of trade size. Larger trades are more likely to have been initiated by investors with superior information and are, therefore, more informative.

In our application the suppliers of liquidity have more information than in the original Glosten and Harris (1988) model. Besides trade direction and trade size they also observe whether the transaction took place in Xetra or in Xetra BEST. The cream skimming argument discussed earlier predicts that traders in Xetra BEST are less likely to possess superior information. But then we should expect that the change in the bid and ask quotes is smaller after a trade in Xetra BEST than after a trade in the Xetra order book. Our modification of the Glosten and Harris (1988) model allows us to test whether this is indeed the case. This is our approach to test the cream skimming hypothesis.

In the following we show how the Glosten and Harris (1988) model can be adapted to the dual market structure of Xetra and Xetra BEST. Let $Q_{t}$ be a trade indicator taking on the value 1 if transaction $t$ is buyer-initiated and -1 if it is seller-initiated. Transaction price and share volume of transaction $t$ are denoted by $P_{t}$ and $V_{t}$, respectively. Let $M_{t}$ denote the midpoint of the best bid and ask quotation in the order book at the time transaction $t$ occurs. We assume that $M_{t}$ evolves according to

$$
M_{t}=M_{t-1}+\left(1-B_{t-1}\right) Z_{t-1}^{X} Q_{t-1}+B_{t-1} Z_{t-1}^{B} Q_{t-1}+\varepsilon_{t}
$$

where $Z_{t}^{J}$ is the adverse selection component of the spread. It is equal to the amount by which the suppliers of liquidity adjust their quotes after observing a transaction. The index $J \in\{X, B\}$ refers to the Xetra order book $(X)$ and Xetra BEST $(B)$, respectively. $B_{t}$ is a dummy variable taking on the value one if transaction $t$ occurs in Xetra BEST and zero otherwise. The

\footnotetext{
16 This is the intuition underlying the Glosten and Milgrom (1985) model.
} 
intuition behind equation (4) is simple. The suppliers of liquidity incorporate the information revealed by transaction $t-1$, measured by the adverse selection component $Z_{t-1}^{J}$, into their bid and ask prices. The adverse selection component represents the information content of the trade. It is allowed to be different for transactions in Xetra and Xetra BEST, respectively. Public information releases, which will also affect the quotes, are incorporated into the zero mean and serially uncorrelated random variable $\varepsilon_{t}$. The adverse selection component is assumed to depend linearly on the size of the transaction,

$$
Z_{t}^{J}=z_{0}^{J}+z_{1}^{J} V_{t}
$$

From (4) and (5) we obtain the change in the quote midpoint

$$
\left(M_{t}-M_{t-1}\right)=z_{0}^{X} Q_{t-1}+z_{1}^{X} Q_{t-1} V_{t-1}+\left(z_{0}^{B}-z_{0}^{X}\right) B_{t-1} Q_{t-1}+\left(z_{1}^{B}-z_{1}^{X}\right) B_{t-1} Q_{t-1} V_{t-1}+\varepsilon_{t}
$$

The bid and ask prices are based on the expected values of the asset conditional upon the characteristics (i.e., direction and size) of the next trade. They further incorporate the temporary component of the spread introduced earlier. For trades in the Xetra order book the transitory component, denoted $C_{t}^{X}$, is assumed to depend linearly on trade size,

$$
C_{t}^{X}=c_{0}^{X}+c_{1}^{X} V_{t}
$$

Consequently, the price for transaction $t$ if it occurs in Xetra can be written as

$$
P_{t}=M_{t}+\left(z_{0}^{X}+z_{1}^{X} V_{t}+c_{0}^{X}+c_{1}^{X} V_{t}\right) Q_{t}+\eta_{t}
$$

where $\left(z_{0}^{X}+z_{1}^{X} V_{t}+c_{0}^{X}+c_{1}^{X} V_{t}\right)$ is the half spread and the zero mean random variable $\eta_{\mathrm{t}}$ captures random noise, rounding effects etc. This formulation implies that the transaction price is contingent upon the size of the trade which is in line with models of limit order markets such 
as Glosten (1994). It is also consistent with our data. Remember that transactions triggered by market orders walking up or down the book are recorded as one transaction at the volumeweighted average price in our data set. The prices of these transactions are clearly contingent on trade size.

Transaction prices in Xetra BEST are not determined independently. Rather, these prices are derived from the bid and ask prices prevailing in the Xetra order book. An investor buying in Xetra BEST pays the current Xetra ask price minus the price improvement. Similarly, an investor selling in Xetra BEST receives the current Xetra bid price plus the price improvement. As noted previously, the size of the price improvement is fixed by the best executor (typically the minimum value of one cent per share) and is not changed during the trading day. Therefore, we treat the price improvement as a constant and denote it by $\imath$. For a transaction occurring in Xetra BEST the transaction price is then

$$
P_{t}=M_{t}+\left(z_{0}^{X}+z_{1}^{X} V_{t}+c_{0}^{X}+c_{1}^{X} V_{t}-\imath\right) Q_{t}+\eta_{t}
$$

Combining (8) and (9) yields the following expression for the transaction price:

$$
\begin{aligned}
P_{t} & =M_{t}+\left(1-B_{t}\right)\left(z_{0}^{X}+z_{1}^{X} V_{t}+c_{0}^{X}+c_{1}^{X} V_{t}\right) Q_{t}+B_{t}\left(z_{0}^{X}+z_{1}^{X} V_{t}+c_{0}^{X}+c_{1}^{X} V_{t}-\imath\right) Q_{t}+\eta_{t} \\
& =M_{t}+\left(z_{0}^{X}+z_{1}^{X} V_{t}+c_{0}^{X}+c_{1}^{X} V_{t}\right) Q_{t}-\imath B_{t} Q_{t}+\eta_{t} .
\end{aligned}
$$

First-differencing, inserting (6) and rearranging terms yields our basic model

$$
\begin{aligned}
& \Delta P_{t}=z_{0}^{X} Q_{t}+z_{1}^{X} Q_{t} V_{t}+c_{0}^{X}\left(Q_{t}-Q_{t-1}\right)+c_{1}^{X}\left(Q_{t} V_{t}-Q_{t-1} V_{t-1}\right) \\
& +\left(z_{0}^{B}-z_{0}^{X}\right) B_{t-1} Q_{t-1}+\left(z_{1}^{B}-z_{1}^{X}\right) B_{t-1} Q_{t-1} V_{t-1}-\imath\left(B_{t} Q_{t}-B_{t-1} Q_{t-1}\right)+v_{t}
\end{aligned}
$$

where $v_{t}=\varepsilon_{t}+\eta_{t}-\eta_{t-1}$. Equation (11) can be estimated by OLS to obtain estimates of both the transitory and the permanent component of the spread as a function of trade size. We obtain 
two such sets of estimates, one for transactions in the Xetra order book (denoted by a superscript X) and one for transactions in Xetra BEST (denoted by a superscript B). Note that for $B_{t}=B_{t-1}=0$, equation (11) reduces to equation (2) in Glosten and Harris (1988).

We have argued that the Glosten and Harris (1988) model is more adequate for our purpose than the Huang and Stoll (1997) and Madhavan, Richardson and Roomans (1997) models because only the Glostan and Harris model allows the components of the spread to depend on trade size. However, given the popularity of the Huang and Stoll and Madhavan, Richardson and Roomans models, and as a robustness check, we also estimate a version of our model which assumes a constant trade size $\overline{\mathrm{V}}$. The adverse selection component and the transitory component in the Xetra order book are then $\theta^{\mathrm{X}} \equiv \mathrm{z}_{0}^{\mathrm{X}}+\mathrm{z}_{\mathrm{i}}^{\mathrm{X}} \overline{\mathrm{V}} ; \phi^{\mathrm{X}} \equiv \mathrm{c}_{0}^{\mathrm{X}}+\mathrm{c}_{\mathrm{i}}^{\mathrm{X}} \overline{\mathrm{V}}$. The adverse selection component in Xetra BEST is $\theta^{\mathrm{X}} \equiv \mathrm{z}_{0}^{\mathrm{B}}+\mathrm{z}_{\mathrm{i}}^{\mathrm{B}} \overline{\mathrm{V}} \cdot{ }^{17}$ Substituting these expressions into equation (11) yields the following simplified model:

$$
\Delta P_{t}=\theta^{X} Q_{t}+\phi^{X}\left(Q_{t}-Q_{t-1}\right)+\left(\theta^{B}-\theta^{X}\right) B_{t-1} Q_{t-1}-\imath\left(B_{t} Q_{t}-B_{t-1} Q_{t-1}\right)+v_{t}^{*}
$$

This model assumes a constant trade size $\bar{V}$, and $\theta^{J}, J \in\{X, B\}$, is the adverse selection component in market $J$, adapted to this constant trade size. Similarly, $\phi^{X}$ denotes the transitory component of the spread, adapted to the constant trade size.

17 Note that there is no transitory component in Xetra BEST. This holds because prices in Xetra BEST are derived from the bid and ask quotes in Xetra. Transactions in Xetra BEST are executed at a price equal to the Xetra price plus / minus the price improvement $\mathbf{l}$ 
Note that for $B_{t}=B_{t-1}=0$ equation (12) corresponds to equation (5) in Huang and Stoll (1997), and it also corresponds to equation (4) in Madhavan, Richardson and Roomans (1997) with the additional restriction that $Q_{t}$ is serially uncorrelated.

\subsection{Estimation Results}

We start our analysis with the estimation of our basic model. For this purpose we estimate equation (11) for each stock using OLS and compute Newey-West standard errors to account for the serial correlation caused by the specific structure of the disturbance term $v_{t}$. Results are presented in Table III.

The explanatory variables explain a significant portion of the price changes. This is evidenced by $\mathrm{R}^{2}$ values ranging from 0.27 to 0.34 . The adverse selection component for regular Xetra trades is significant for all sample stocks. It depends positively on trading volume (i.e., $\left.z_{1}^{X}>0\right)$ as models such as Glosten (1994) predict. The transitory component is characterized by a positive intercept and a negative relation to trade size (i.e., $c_{1}^{X}<0$ ). This suggests economies of scale in the execution of trades. ${ }^{18}$ These are, however, overcompensated by the increase in adverse selection costs, as is evinced by the fact that $z_{1}^{X}>\left|c_{1}^{X}\right|$ for all sample stocks.

The adverse selection component in Xetra BEST is significantly smaller than its Xetra counterpart. The intercept $z_{0}^{B}$ is significantly lower than $z_{0}^{X}$ for all sample stocks whereas there are

18 The bid-ask spread must offer suppliers of liquidity a compensation for the order processing costs. These costs are likely to be, at least partially, fixed per transaction. Consequently, the required compensation on a pershare basis (which is reflected in the order processing component of the spread) is declining in trade size. This provides an economic intuition for the negative value of the parameter $c_{1}$. 
(with one exception ${ }^{19}$ ) no significant differences in the slope coefficients $z_{1}^{B}$ and $z_{1}^{X}$ which measure the relation between the adverse selection cost and trade size. A comparison of $z_{0}^{B}$ to $z_{0}^{X}$ reveals that the adverse selection component for small Xetra BEST trades is close to zero. Thus, there is clear evidence of cream skimming.

\section{Insert Table III about here}

The most surprising results are those for the effective price improvement $\imath$. We should expect a positive coefficient close to 0.01 , corresponding to the minimum price improvement of one cent. It turns out, however, that the effective price improvement is smaller than 0.01 for all sample stocks and is even significantly negative for three of the sample stocks. We will provide an explanation for this result in section 4.4.

Table IV presents the results of the restricted model (12) which assumes a constant trade size. They are perfectly consistent with those of the unrestricted model. The Xetra adverse selection component, $\left(\theta^{X}\right)$ is positive and significant for all stocks. In all cases the $\theta^{X}$ estimates are slightly larger than the estimates of $z_{0}^{X}$ in Table III. This is expected, given that $z_{0}^{X}$ is the intercept of the adverse selection component (i.e., $z_{0}^{X}$ is the adverse selection component for a trade of size zero) and that the adverse selection component was shown to increase with trade size. The estimates of the transitory components, $\phi^{X}$, are also significant and positive, and

19 As for this stock (DBK) the slope in Xetra BEST is larger, the adverse selection component will be larger in Xetra BEST than in Xetra for large trades. The trade size that makes the adverse selection component in both trading systems equal is 1,437 shares and is larger than the maximum trade size observed in Xetra BEST which is 1,200 shares. We can thus safely conclude that the adverse selection component is smaller in Xetra BEST for DBK, too. 
slightly smaller in magnitude than the estimates of $c_{0}^{X}$. This is again expected since $c_{0}^{X}$ is the intercept of the transitory component (i.e., $c_{0}^{X}$ is the transitory component for a trade of size zero), and the transitory component was shown to decrease with trade size.

The adverse selection component in Xetra BEST, $\theta^{B}$, is significantly smaller than $\theta^{X}$. In fact, it is close to zero for most of the sample stocks. This is also consistent with the results of the unrestricted model. The estimates of the effective price improvement are slightly larger than those in Table III but show the same pattern. They are all smaller than 0.01 , and we obtain significant negative estimates for the same three stocks as before.

Insert Table IV about here

The results of the trade indicator models can be summarized as follows. The restricted and the unrestricted models yield remarkably similar results. There is clear evidence of cream skimming. The adverse selection component is smaller in Xetra BEST for all sample stocks. The mandatory price improvement does not fully compensate for the differences in adverse selection costs. In fact, the effective price improvement is much smaller than the required minimum price improvement of 1 cent and is even negative for three of the sample stocks.

\subsection{Discussion}

The finding that the effective price improvement we estimate is smaller than one cent, and in some cases is even negative, is surprising at first sight. Given that a trade can only be executed in Xetra BEST when the transaction price improves on the price in the order book by (at least) one cent, one would expect that the effective price improvement must be one cent. We offer two, not mutually exclusive, explanations for our surprising finding. The first explanation is 
based on the design of the trading system. Remember from section 2 that customer orders cannot be executed in Xetra BEST when execution would result in a negative or zero spread. This implies that we do not observe executions in Xetra BEST at times when the spread in the order book is one cent or two cents. Thus, conditional upon observing a Xetra BEST trade, the spread in the order book is large.

Consider the following illustrative example: Assume the spread is 1, 2, 3 or 4 cents, each with equal probability. If transactions occur randomly the effective half-spread is $0.5,1,1.5$ or 2 cents with equal probability and thus is 1.25 cents on average. Transactions in Xetra BEST only occur when the spread is 3 or 4 cents, however. The effective half-spread is thus either 0.5 cents $(1.5$ cents minus the 1 cent price improvement) or 1 cent $(2$ cents minus the 1 cent price improvement); on average it is 0.75 cents. The difference in the effective half spread is 0.5 cents $(1.25$ cents for trades in the order book and 0.75 cents for trades in Xetra BEST), only half the magnitude of the price improvement.

The second explanation is based on the timing of transactions. The quoted spread in the Xetra order book is not constant but rather varies over time. Consequently, traders can reduce the effective spread they pay by submitting their market orders at times when the quoted spread is low. Timing a transaction in this way requires real-time information about the prevailing bidask spread. Access to this information is restricted, however. Information on best bid and ask quotations is available via the internet only with a 15 minute delay. Real time data must be purchased. Retail customers whose orders are internalized are unlikely to purchase this information. Consequently they are at an informational disadvantage because they are unable to time the submission of their orders. This, in turn, will increase the average effective spread paid by these customers. We refer to this effect as the timing disadvantage. The timing disad- 
vantage will be larger for stocks which have more pronounced intradaily fluctuations in the spread.

We illustrate the timing disadvantage with a simple example. Assume the spread is either 5 cents or 10 cents. Institutional traders (who trade in the order book) typically have access to real-time information on quoted spreads and thus will tend to trade when the spread is 5 cents. We then observe an average effective half-spread for order book trades of 2.5 cents. Now assume that retail investors whose orders are executed in Xetra BEST do not have access to realtime information. They are thus equally likely to trade on a 5-cent or on a 10-cent spread. The observed effective half spread (taking the price improvement into account) is either 1.5 cent or 4 cents; the average is 2.75 cents and is larger than the average effective half-spread for order book trades. This example is, of course, very stylized. It does illustrate, however, how the lack of access to real-time quote information may affect effective spreads in the retail segment of the market.

The coefficient 1 in our model thus captures three effects, namely, 1) the mandatory price improvement, 2) the fact that, conditional upon observing a trade in Xetra BEST the spread must be larger than 2 cents, and 3) the timing disadvantage of retail investors using Xetra BEST. The relative magnitude of these opposing effects depends on the magnitude of the price improvement compared to the size of the spread and the magnitude of the intradaily fluctuations of the quoted spread. These fluctuations (as well as the level of the spread) are likely to be larger for higher-priced stocks. ${ }^{20}$ Thus, for higher priced stocks a one cent price improvement is of relatively lower value than the same price improvement for lower-priced stocks. This argument implies that the effective price improvement we are measuring with the parameter 1 
should be negatively related to the price level of the stock. We find supporting evidence for this conjecture. The three stocks with negative effective price improvement are also the stocks with the highest average prices. The rank correlation between the effective price improvement and the average price is -0.71 .

\section{Summary and Conclusion}

This paper provides a detailed analysis of internalization in Xetra BEST. This platform, operated by Deutsche Börse AG as a part of its Xetra system, allows participating banks and brokers to internalize customer order flow. An important feature of the system is that the internalizer has to grant a price improvement of (at least) one cent. Thus, the customer order will be filled at a price which is more favorable than the price in the Xetra order book at the time of order submission.

It has been argued that internalization results in cream skimming. Internalized orders are small orders submitted by retail customers. These customers typically do not possess private information on the value of the securities they trade. Consequently, the internalized orders are "easy-to-fill" orders which are unlikely to be affected by adverse selection effects. Consequently, the adverse selection component of the spread will be lower for these orders, and executing them will be profitable for the internalizer.

We test the cream skimming hypothesis using a sample of DAX stocks. We use two methodologies. The first is a spread decomposition similar to the two-way decomposition proposed by Huang and Stoll (1996). We find that realized spreads are unanimously higher in Xetra BEST even after taking into account the mandatory price improvement. This indicates that

20 Remember that we measure spreads in Euro, not in percentage terms. 
internalization is indeed profitable. We then proceed by developing a structural model of the specific dual market structure under scrutiny. When estimating this model we find that adverse selection costs in Xetra BEST are considerably smaller than those in the main market. This is again consistent with the cream skimming hypothesis.

In conclusion, we find clear evidence in favor of the cream skimming hypothesis. We wish to stress, though, that this does not imply that internalization is bad for the customer. On the contrary, a customer who has her order internalized receives a price improvement which makes execution in Xetra BEST more favorable than execution of the same order in the Xetra order book. Our results do imply, however, that the price improvement which the customer receives is smaller than the cost advantage to the internalizer. Thus, internalization may be profitable both for the customer and the internalizer. The size of the price improvement determines how the profit is shared between the internalizer and the customer. In this respect, the new version of Xetra BEST, in operation since 2007, is more favorable to the internalizers because the required price improvement has been reduced to 0.1 cent. 


\section{References}

Battalio, R. (1997), 'Third Market Broker-Dealers: Cost Competitors or Cream Skimmers?' Journal of Finance, Vol.52, No.1 (March), pp.341-352.

Battalio, R., Holden, C. (2001), 'A Simple Model of Payment for Order Flow, Internalization, and Total Trading Cost', Journal of Financial Markets, Vol.4, No.1 (January), pp.33-71.

Battalio, R., Greene J., Jennings,R. (1997), 'Do Competing Specialists and Preferencing Dealers Affect Market Quality?', Review of Financial Studies, Vol.10, No.4 (Winter), pp.969-993.

Battalio, R., Jennings, R., Selway, J. (2001), 'The Relationship Among Market-Making Revenue, Payment for Order Flow, and Trading Costs for Market Orders', Journal of Financial Services Research, Vol.19, No.1 (February), pp.39-56.

Biais, B., Davydoff, D. (2002), 'Internalization, Investor Protection and Market Quality', Working Paper (July).

Bloomfield, R., O’Hara, M. (1998), 'Does Order Preferencing Matter?', Journal of Financial Economics, Vol.50, No.1 (October), pp.3-37.

Chakravarty, S. (2001), 'Stealth-Trading: Which Traders' Trades Move Stock Prices?', Journal of Financial Economics, Vol.61, No.2 (August), pp.289-307.

Easley, D., Kiefer, N., O’Hara, M. (1996), 'Cream-Skimming or Profit Sharing? The Curious Role of Purchased Order Flow', Journal of Finance, Vol.51, No.3 (July), pp.811-833.

Glosten, L. (1994), 'Is the Electronic Open Limit Order Book Inevitable?', Journal of Finance, Vol.49, No.4 (September), pp.1127-1161. 
Glosten, L., Harris, L. (1988), 'Estimating the Components of the Bid-Ask Spread', Journal of Financial Economics, Vol.21, No.1 (May), pp.123-142.

Hansch, O., Naik, N., Viswanathan, S. (1999), 'Preferencing, Internalization, Best Execution, and Dealer Profits', Journal of Finance, Vol.54, No.5 (October), pp.1799-1828.

Huang, R., Stoll, H. (1996), 'Dealer versus Auction Markets: A Paired Comparison of Execution Costs on NASDAQ and the NYSE', Journal of Financial Economics, Vol.41, No.3 (July), pp.313-357.

Huang, R., Stoll, H. (1997), 'The Components of the Bid-Ask Spread: A General Approach', Review of Financial Studies, Vol.10, No.4 (Winter), pp.995-1034.

Kandel, E., Marx, L. (1999), 'Payments for Order Flow on Nasdaq', Journal of Finance, Vol.54, No.1 (February), pp.35-66.

Linnainmaa, J. (2003), 'Who Makes the Limit Order Book? Implications for Contrarian Strategies, Attention-Grabbing Hypothesis, and the Disposition Effect', Working Paper, (University of California Los Angeles, October).

Madhavan, A., Richardson, M., Roomans, M. (1997), 'Why Do Securities Prices Change? A Transaction-Level Analysis of NYSE Stocks', Review of Financial Studies, Vol.10, No.4 (Winter), pp.1035-1064.

Maher, O., P. Swan and J. Westerholm (2008): Twilight Falls on the Limit Order Book: Endogeneity and the Demise of Broker Identity. Working Paper, March.

Parlour, Ch., Rajan, U. (2001), 'Payment for Order Flow', Working Paper (Carnegie Mellon University, May). 
Peterson, M., Sirri, E. (2003), 'Order Preferencing and Market Quality on U.S. Equity Exchanges', Review of Financial Studies, Vol.16, No.2 (Summer), pp.385-415. 


\section{Table I: Descriptive Statistics}

The table presents descriptive statistics for our sample. The first column identifies the stock. Stocks are sorted by total $€$ trading volume in the sample period. Columns 2 - 4 show the number of transactions, the average trade size in shares and the average trade size in $€$ for regular order book trades. Columns 5 - 7 provide the same information for Xetra BEST trades.

\begin{tabular}{ccccccccc} 
& \multicolumn{3}{c}{ Xetra } & & \multicolumn{4}{c}{ Xetra BEST } \\
\cline { 2 - 3 } \cline { 7 - 8 } $\begin{array}{c}\text { Stock } \\
\text { id }\end{array}$ & $\begin{array}{c}\text { \# of trans- } \\
\text { actions }\end{array}$ & $\begin{array}{c}\text { avg. trade } \\
\text { size, shares }\end{array}$ & $\begin{array}{c}\text { avg. trade } \\
\text { size, } €\end{array}$ & & $\begin{array}{c}\text { \# of trans- } \\
\text { actions }\end{array}$ & $\begin{array}{c}\text { avg. trade } \\
\text { size, shares }\end{array}$ & $\begin{array}{c}\text { maximum } \\
\text { trade size, } \\
\text { shares }\end{array}$ & $\begin{array}{c}\text { avg. trade } \\
\text { size, } €\end{array}$ \\
\hline DBK & 289,425 & $1,450.03$ & $65,022.85$ & & 3,009 & 174 & 1,200 & 7,770 \\
DCX & 324,365 & $1,466.66$ & $47,597.64$ & & 8,687 & 160 & 1,800 & 5,501 \\
EOS & 221,584 & $1,285.71$ & $56,346.44$ & & 1,741 & 156 & 1,020 & 6,810 \\
BAY & 195,192 & $1,694.96$ & $34,189.54$ & & 2,946 & 306 & 3,000 & 6,128 \\
RWE & 155,967 & $1,204.76$ & $34,040.08$ & & 1,370 & 219 & 2,000 & 6,143 \\
SCH & 110,351 & 809.52 & $36,038.15$ & & 1,920 & 157 & 1,400 & 6,979 \\
TKA & 91,177 & $2,079.62$ & $22,614.20$ & & 1,214 & 440 & 5,000 & 4,769 \\
DPW & 70,789 & $1,629.19$ & $16,523.77$ & & 1,484 & 405 & 5,000 & 4,054
\end{tabular}




\section{Table II: Realized Spreads}

Panel A shows average realized spreads for the sample stocks. Realized spreads are calculated as follows: We match a buyer-initiated trade with the first seller-initiated trade after at least 5 minutes, and similarly we match a seller-initiated trade with the first buyer-initiated trade after at least 5 minutes. Let $s_{t}^{R}$ be the realized spread for transaction $t, P_{t}^{j} ; j \in\{a, b\}$, the transaction price where $a$ and $b$ denote a buyer- and a seller-initiated trade, respectively, and let $\tau$ (chosen to be 5 minutes in our application) be the time interval between the matched trades. Then the expressions $s_{t}^{R}=P_{t}^{a}-P_{t+\tau}^{b}$ and $s_{t}^{R}=P_{t+\tau}^{a}-P_{t}^{b}$ if the initial transaction was at the ask and the bid, respectively, yield an estimate of the realized spread (not half-spread). Column 2 shows average realized spreads for regular order book trades. Column 3 excludes trades with a size larger than the maximum Xetra BEST trade size for the stock in question. Column 4 contains average realized spreads for trades in Xetra BEST. The last column presents the t-statistics for a test of the null hypothesis that the averages given in columns 3 and 4 are equal.

Panel B presents the results of the regression $s_{t}^{R}=\gamma_{0}+\gamma_{1} B_{t}+\gamma_{2} \ln \left(V_{t}\right)+\varepsilon_{t}$ where $B_{t}$ is a dummy variable identifying trades executed in Xetra BEST. Order book trades with a size exceeding the maximum trade size in Xetra BEST are excluded from the estimation. t-values are given in parentheses.

Panel A: Univariate Results

\begin{tabular}{ccccc} 
& $s_{t}^{R}$, Xetra & $\begin{array}{c}s_{t}^{R}, \text { Xetra; Trade size } \\
\leq \text { maximum size in } \\
\text { Xetra BEST }\end{array}$ & $s_{t}^{R}$, Xetra BEST & $\begin{array}{c}\text { t-value } \\
\text { (3) vs. (4) }\end{array}$ \\
\hline DBK & 0.0081 & 0.0105 & 0.0242 & 4.29 \\
DCX & 0.0107 & 0.0119 & 0.0198 & 5.78 \\
EOS & 0.0078 & 0.0091 & 0.0242 & 4.26 \\
BAY & 0.0056 & 0.0061 & 0.0105 & 2.81 \\
RWE & 0.0051 & 0.0052 & 0.0153 & 3.61 \\
SCH & 0.0128 & 0.0146 & 0.0378 & 6.28 \\
TKA & 0.0059 & 0.0062 & 0.0074 & 0.90 \\
DPW & 0.0049 & 0.0052 & 0.0065 & 1.15 \\
average (unweighted) & 0.0076 & 0.0086 & 0.0182 &
\end{tabular}

Panel B: Regression Results

\begin{tabular}{cccc} 
& $\gamma_{0}$ & $\gamma_{1}$ & $\gamma_{2}$ \\
\hline \multirow{2}{*}{ DBK } & 0.0349 & 0.0086 & -0.0042 \\
& $(16.72)$ & $(2.77)$ & $(11.87)$ \\
DCX & 0.0293 & 0.0039 & -0.0029 \\
& $(23.42)$ & $(2.95)$ & $(14.11)$ \\
EOS & 0.0206 & 0.0127 & -0.0020 \\
& $(10.15)$ & $(3.56)$ & $(5.80)$ \\
BAY & 0.0137 & 0.0030 & -0.0012 \\
& $(12.89)$ & $(2.05)$ & -0.0007 \\
RWE & 0.0098 & 0.0091 & $(3.23)$ \\
& $(6.85)$ & $(3.63)$ & -0.0045 \\
SCH & 0.0402 & 0.0181 & $(10.02)$ \\
& $(15.42)$ & $(4.84)$ & -0.0010 \\
TKA & 0.0128 & 0.00001 & $(8.67)$ \\
& $(16.63)$ & $(0.01)$ & -0.0014 \\
DPW & 0.0143 & -0.0001 & $(12.52)$
\end{tabular}




\section{Table III: Trade Indicator Model - Unrestricted version}

The table presents the results of the regression

$$
\begin{aligned}
\Delta P_{t}= & z_{0}^{X} Q_{t}+z_{1}^{X} Q_{t} V_{t}+c_{0}^{X}\left(Q_{t}-Q_{t-1}\right)+c_{1}^{X}\left(Q_{t} V_{t}-Q_{t-1} V_{t-1}\right)+\left(z_{0}^{B}-z_{0}^{X}\right) B_{t-1} Q_{t-1} \\
& +\left(z_{1}^{B}-z_{1}^{X}\right) B_{t-1} Q_{t-1} V_{t-1}-\imath\left(B_{t} Q_{t}-B_{t-1} Q_{t-1}\right)+v_{t}
\end{aligned}
$$

where $\Delta P_{t}=\left(P_{t}-P_{t-1}\right)$ denotes the price change, $Q_{t}$ is a trade indicator variable (1 if the trade is buyer-initiated, 0 if it is seller-initiated), $V_{t}$ is the trade size in shares and $B_{t}$ is a dummy variable identifying trades in Xetra BEST. $\mathrm{t}$-values in parentheses are based on Newey-West standard errors.

\begin{tabular}{ccccccccc} 
& $z_{0}^{X}$ & $z_{1}^{X}$ & $c_{0}^{X}$ & $c_{1}^{X}$ & $\left(z_{0}^{B}-z_{0}^{X}\right)$ & $\left(z_{1}^{B}-z_{1}^{X}\right)$ & $i$ & $\mathrm{R}^{2}$ \\
\hline \multirow{2}{*}{ DBK } & 0.00826 & $2.18 \mathrm{E}-6$ & 0.01100 & $-9.63 \mathrm{E}-7$ & -0.00813 & $5.66 \mathrm{E}-6$ & -0.00508 & 0.301 \\
& $(75.21)$ & $(36.18)$ & $(98.17)$ & $(17.52)$ & $(9.31)$ & $(2.57)$ & $(6.44)$ & \\
& 0.00564 & $1.56 \mathrm{E}-6$ & 0.00909 & $-6.32 \mathrm{E}-7$ & -0.00633 & $7.28 \mathrm{E}-7$ & 0.00097 & 0.342 \\
DCX & $(77.78)$ & $(39.71)$ & $(117.93)$ & $(17.12)$ & $(17.96)$ & $(0.72)$ & $(3.17)$ & \\
& 0.00848 & $1.96 \mathrm{E}-6$ & 0.00899 & $-6.53 \mathrm{E}-7$ & -0.00657 & $-3.55 \mathrm{E}-6$ & -0.00341 & 0.291 \\
EOS & $(74.83)$ & $(29.24)$ & $(80.97)$ & $(11.35)$ & $(2.54)$ & $(0.44)$ & $(2.55)$ & \\
& 0.00455 & $1.28 \mathrm{E}-6$ & 0.00592 & $-4.30 \mathrm{E}-7$ & -0.00511 & $2.54 \mathrm{E}-7$ & 0.00191 & 0.313 \\
BAY & $(65.03)$ & $(40.35)$ & $(87.99)$ & $(16.37)$ & $(9.50)$ & $(0.33)$ & $(4.32)$ & \\
& 0.00708 & $1.92 \mathrm{E}-6$ & 0.00622 & $-5.41 \mathrm{E}-7$ & -0.00680 & $-2.38 \mathrm{E}-6$ & 0.00026 & 0.271 \\
RWE & $(64.30)$ & $(28.31)$ & $(58.53)$ & $(9.56)$ & $(6.18)$ & $(0.99)$ & $(0.30)$ & \\
& 0.01019 & $3.09 \mathrm{E}-6$ & 0.01415 & $-9.05 \mathrm{E}-7$ & -0.00791 & $1.44 \mathrm{E}-6$ & -0.00601 & 0.280 \\
SCH & $(43.53)$ & $(12.98)$ & $(60.12)$ & $(5.45)$ & $(5.60)$ & $(0.43)$ & $(4.70)$ & \\
& 0.00283 & $7.07 \mathrm{E}-7$ & 0.00509 & $-1.97 \mathrm{E}-7$ & -0.00247 & $5.96 \mathrm{E}-8$ & 0.00282 & 0.317 \\
TKA & $(36.72)$ & $(24.33)$ & $(66.85)$ & $(8.35)$ & $(3.72)$ & $(0.11)$ & $(4.94)$ & \\
& 0.00303 & $8.68 \mathrm{E}-7$ & 0.00507 & $-3.91 \mathrm{E}-7$ & -0.00264 & $8.81 \mathrm{E}-8$ & 0.00276 & 0.296 \\
DPW & $(26.89)$ & $(14.75)$ & $(57.01)$ & $(11.50)$ & $(4.47)$ & $(0.15)$ & $(5.47)$ & \\
& & & & & & & &
\end{tabular}




\section{Table IV: Trade Indicator Model - Constant Trade Size}

The table presents the results of the regression

$$
\Delta P_{t}=\theta^{X} Q_{t}+\phi^{X}\left(Q_{t}-Q_{t-1}\right)+\left(\theta^{B}-\theta^{X}\right) B_{t-1} Q_{t-1}-\imath\left(B_{t} Q_{t}-B_{t-1} Q_{t-1}\right)+v_{t}^{*}
$$

where $\Delta P_{t}=\left(P_{t}-P_{t-1}\right)$ denotes the price change, $Q_{t}$ is a trade indicator variable ( 1 if the trade is buyer-initiated, 0 if it is seller-initiated) and $B_{t}$ is a dummy variable identifying trades in Xetra BEST. t-values in parentheses are based on Newey-West standard errors.

\begin{tabular}{cccccc} 
& $\theta^{X}$ & $\phi^{X}$ & $\left(\theta^{B}-\theta^{X}\right)$ & $\imath$ & $\mathrm{R}^{2}$ \\
\hline \multirow{2}{*}{ DBK } & 0.01150 & 0.00952 & -0.01021 & -0.00345 & 0.296 \\
& $(153.12)$ & $(114.57)$ & $(13.48)$ & $(4.38)$ & \\
DCX & 0.00800 & 0.00810 & -0.00847 & 0.00223 & 0.336 \\
& $(157.64)$ & $(136.22)$ & $(28.38)$ & $(7.32)$ & \\
EOS & 0.01105 & 0.00810 & -0.00948 & -0.00193 & 0.287 \\
& $(135.87)$ & $(92.47)$ & $(4.20)$ & $(1.44)$ & \\
BAY & 0.00679 & 0.00512 & -0.00707 & 0.00315 & 0.303 \\
& $(128.60)$ & $(95.40)$ & $(15.75)$ & $(7.12)$ & \\
RWE & 0.00944 & 0.00552 & -0.00945 & 0.00163 & 0.264 \\
& $(113.87)$ & $(66.81)$ & $(10.34)$ & $(1.89)$ & \\
SCH & 0.01273 & 0.01338 & -0.01004 & -0.00455 & 0.277 \\
& $(78.98)$ & $(69.72)$ & $(8.18)$ & $(3.56)$ & \\
TKA & 0.00432 & 0.00467 & -0.00377 & 0.00370 & 0.307 \\
& $(75.61)$ & $(78.85)$ & $(6.40)$ & $(6.48)$ & \\
DPW & 0.00448 & 0.00441 & -0.00380 & -0.00341 & 0.289
\end{tabular}




\section{CFS Working Paper Series:}

\begin{tabular}{lll} 
No. & Author(s) & Title \\
\hline $2011 / 02$ & $\begin{array}{l}\text { Jördis Hengelbrock } \\
\text { Erik Theissen } \\
\text { Christian Westheide }\end{array}$ & Market Response to Investor Sentiment \\
$2011 / 01$ & $\begin{array}{l}\text { Mathias Hoffmann } \\
\text { Michael U. Krause } \\
\text { Thomas Laubach }\end{array}$ & $\begin{array}{l}\text { Long-run Growth Expectations and "Global } \\
\text { Imbalances" }\end{array}$ \\
$2010 / 26$ & $\begin{array}{l}\text { Ester Faia } \\
2010 / 25\end{array}$ & $\begin{array}{l}\text { Ignazio Angeloni } \\
\text { Ester Faia } \\
\text { Roland Winkler }\end{array}$ \\
\end{tabular}

2010/24 Roman KräussI

Andre Lucas

Arjen Siegmann

Risk Aversion under Preference Uncertainty

2010/23 Carmen Lee

Roman Kräussl

Andre Lucas

Leo Paas

2010/22 Steffen Juranek

Uwe Walz

Why Do Investors Sell Losers? How

Adaptation to Losses Affects Future

Capitulation Decisions

Vertical Integration, Competition, and Financial Exchanges: Is there Grain in the Silo?

2010/21 Marcel Marekwica Michael Stamos

Optimal life cycle portfolio choice with housing market cycles

2010/20 Mahmoud Botshekan

Cash Flow and Discount Rate Risk in Up and Roman KraeussI Andre Lucas

Down Markets: What Is Actually Priced?

2010/19 Nikolaus Hautsch

Peter Malec

Melanie Schienle

Capturing the Zero: A New Class of ZeroAugmented Distributions and Multiplicative Error Processes

Copies of working papers can be downloaded at http://www.ifk-cfs.de 